\title{
TRAINING PUBLIC SERVICE INTERPRETERS AND TRANSLATORS IN THE LEGAL CONTEXT
}

\author{
Carmen Valero Garces
}

\section{doi: 10.18355/PG.2016.5.2.320-336}

\begin{abstract}
Formal training and practice in public service interpreting and translating (PSIT), also known as community interpreting, has been sparking growing interest in Translation Studies (TS). For this field to develop, training and practice need to find common ground with society's needs and the actual professional practice. Based on a case study, the Masters in Intercultural Communication, Interpreting and Translating in Public Services (MICIT) at the University of Alcalá (UAH), Madrid, Spain, an attempt to integrate training, practice and market needs is described and assessed. The MICIT covers translation and interpreting in different settings, although this paper focuses on the legal domain. Data are drawn from the last six academic years (2006 - 2012). The key elements of the existing debate between LIT and PSIT are first introduced, defining some concepts and discussing areas of study as well as the connections between PSIT and LIT; secondly, the postgraduate programme at UAH is described, focusing on LIT modules; thirdly, the integration of internships and research in the programme is

320 further considered and assessed. Results of research within the legal context carried out by postgraduate students are then exposed. While emphasizing the usefulness of research in TS being an integral part of the training of legal interpreters and translators, I will mention some of the challenges that remain.
\end{abstract}

\section{Key words}

public service interpreting and translation, community interpreting, training, professionalization, research, legal interpreting and translation

\section{Introduction}

Since the last decades of the $20^{\text {th }}$ century, public service interpreting and translating (PSIT) have slowly been gaining respect both in the academic and research arenas. The consolidation of international conferences (Critical Link, PSIT at University of Alcalá), the increasing number of publications (Rudvin - Tomassini, 2011; Corsellis, 2008; Hale, 2007; Kainz - Prunc - Schogler, 2011; Valero Garces - Vitalaru, 2014), the establishment of different types of postgraduate training programs (Heriot Watt University, Middelsex University, University of Alcalá) or continuing education courses, seminars and workshops are signs of increased visibility. Yet several experts and practitioners (Hale, 2007; Corsellis, 2008; Valero Garces, 2008, 2013; Hale Napier, 2013; Mikkelson, 2014; Sasso - Malli, 2014) from countries with greater experience (Australia, Canada, Sweden, UK, USA) and from other countries of more recent addition (France, Germany, Italy, Portugal, Spain) continue to emphasise the need for further research in order to overcome 
barriers to the professionalization of PSIT. Some of the barriers brought up in the literature are the need for specialized research, the lack of a connection between research and practice, and the difficulty in accessing the labour market.

The training programme in PSIT that has been offered at the University of Alcalá (UAH), Madrid, since 2001 was born with the intention to break down such barriers. The programme started as a series of seminars

, workshops and continuing education courses offered in the main minority languages spoken by migrants at that time. Nowadays, the Masters in Intercultural Communication, Interpreting and Translating in Public Services (MICIT) is offered, and it has gained both national and European official recognition as a member of the EMT network (EMT, 2014). The curriculum is based on three interconnected pillars: training, research and practice, and it is made up of five modules focusing on different topics. Three of these modules are completely or partially focused on the legal domain -Translation and Interpreting in the Legal and Administrative setting; Internships; and Research in PSIT. My intention is to present the results and implications for the future development and professionalization of PSIT as well as for the training of legal interpreters and translators (LIT) by concentrating on the legal domain within the framework of PSIT.

\section{An open debate. Some definitions and the connection between PSIT and LIT}

If we use human rights as a point of departure, we are bound to find connections between PSIT and LTI. Establishing their relationship and limits is another question. PSIT is generally considered as an activity (interpreting and translating) that enables people who do not speak the official language(s) of the country to communicate with public service providers, thus facilitating equal access to legal services, healthcare, education, and social services (Wadensjo, 1998: 33; Mikkelson, 1996: 126). PSIT can take place in police stations, immigration offices, social services offices, healthcare centres, schools, and other similar places. The recipients/customers usually belong to specific cultural and linguistic minority groups and generally possess an educational and economic level inferior to that of the majority group. Furthermore, they often do not know or completely grasp the new social reality of the country. On the other hand, the service providers - usually from the majority group - do not always understand the minority group's language and rarely understand their culture. It is this imbalance on both sides which forces the development of different strategies to achieve communication.

PSIT implies a bidirectional and dialogic interpreting and translation activity that takes place in communicative settings among speakers of different languages for the purpose of accessing services. The tasks required from public service interpreters usually involve interpreting for social services (in government agencies, schools, and community centres), interpreting in healthcare and medical settings, or interpreting in administrative or legal settings such as police stations, government offices or in situations with legal implications, such as interpreting in a hospital where the client needs to sign 
an informed consent or in judicial offices and legal settings when the client needs help accessing services. From my perspective, and joining forces with many other researchers, LIT y PSIT are two fields of study and practice that share some characteristics and differences, but which cannot be excluded from one another.

However, no consensus has been reached on an international level regarding the inclusion or exclusion of LIT from PSIT. A brief review of the opinions of some well-known PSIT practitioners as well as PSIT researchers and trainers illustrates the open debate and also helps to reinforce the relationship between LIT and PSIT. The Routledege Handbook of Translation Studies (Millan - Bartrina, 2013: vii) considers legal interpreting to be separate from community interpreting. Other authors consider legal interpretation to be a broader term than court interpreting, excluding community interpreting from the latter, but including it in the domain of the profession.

In Canada, Sasso, executive director of Critical Link International, and Mali (Sasso - Malli, 2014: 43), find that there are ties which inevitably bind court interpreting to community interpreting. This is true for at least two reasons: a) court interpreting often involves the same practitioners as those engaged in community and health interpreting and b) it can be an interpreting activity that occurs at a community level.

In Australia, Hale (2007: 64-91) dedicates a full chapter (Chapter 3. Interdisciplinarity: Community Interpreting in the Legal Context) to a description of the main legal setting in which community interpreters work, outlining the most salient issues surrounding interpreting in this setting, and stressing the need for mutual understanding and collaboration between legal interpreters and other professionals working in the legal field to achieve optimum results. Referring to community interpreting in the legal context:

This specialized branch of Community Interpreting is often referred to as Legal Interpreting, which comprises a variety of legal domains such as police interviews and interrogations, lawyer-client conferences, tribunal hearings and court hearings and trials. (Hale, 2007: 65)

Hale (2007: 65) further remarks: "These different domains share the underlying legal system they serve, legal concepts and some of their discourses." She also stresses the fact that each of these domains differs from the others depending on factors such as the relationship between interlocutors, the goal of the interaction, the privacy and the formality of the event, the roles of the participants, the role of language, and "as a consequence, the implications for interpreters" (65).

In USA, Bancroft and Rubio-Fitzpatrick (2009: vii) define community interpreting as "interpreting that takes place in any community setting, with a particular focus on government and non-profit community services, particularly [in] health care, education and human and social services", though they mention the legal setting as well.

Mikkelson (2014: 10) maintains a more open stance and insists: 
I have asserted elsewhere (Mikkelson, 1996: 77) that "because the services are provided to the residents of the community in which the interpreting takes place, not to conference delegates, diplomats, or professional traveling abroad to conduct business", they [services] do include court interpreting.

Benmaman (1997: 178) prefers to stay out of the debate and considers that "legal interpreting by any other name is still legal interpreting".

In UK and some other EU countries such as for example Spain for example, the term public service interpreting is more extensively used, mainly after the institutional decision in 1990 when the Institute of Linguists in UK adopted public service interpreting as its nomenclature (Corsellis, 2008: 4-7). Corsellis (4) defines public service interpreting and translation as "the interpreting and translation carried out in the context of the public services, where service users do not speak the majority language of the country". And considering that the term "public service' refers mainly to those services that are provided for the public by central or local government, Corsellis includes in PSIT "legal, health and the range of social services such as housing, education and environmental health".

Pöchhacker (2004: 15), talking from Austria, states that healthcare interpreting and legal interpreting are "the most significant institutional domains" of what he calls community-based interpreting.

Perez and Wilson (2011: 258-9) present a particular case of study on community interpreting - the interlinked approach, and they point out that the programme is "grounded in the reality of a specific local context and focused on interpreting in legal and more specifically police settings" (243).

Other elements which lead us to establish points of contact and to insist that it is appropriate to include certain aspects of the legal domain in its broadest sense within PSIT are, on one hand, the characteristics of many interpreters working in the public sector, who tend to be bilingual employees. These employees, apart from performing their jobs, fulfill other roles such as interpreting, though they are not included as interpreters in the statistics. They are the "adjunct" or "dual interpreters" as Bancroft and Kickatrick (2009: xx) call them, with little to no training in translation and interpreting. Likewise, there are many translators and interpreters who work in both public services and in the courts when called upon to do so. In both cases there is a certain percentage who have received little training, something that the majority agree should be insisted upon if the status of the profession is to be raised. And there is in fact a certain proliferation of courses and workshops in which students practice or are taught skills or strategies related to the transmission of information from one language to another or in which study is directed at the ethical principles and standards of conduct to be followed. We should also include within this debate the issue of training as Mikkelson (2014: 9) frames it: "Whether or not PSI includes services provided in judicial proceedings, similar issues arise in the training of prospective interpreters regardless of where they will work."

In this vein there is certain consensus regarding the knowledge, skills and abilities (KSAs as Mikkelson [2014: 14] calls them) that all interpreters and translators, regardless of the field they work in, must dominate and which 
therefore must form part of the syllabus for training programs and be included in the curriculum (Hale, 2007: 189; Valero Garces, 2011: 137; Rudvin - Tomassini, 2011: 79-87). The content, though, will vary according to the setting for which students are being prepared.

On the other hand, there are many trainers and scholars within PSIT who agree that this training cannot be rudimentary, just as it is not so in LIT. Rather, as Pérez \& Wilson (2011: 245) indicate:

Given the complexity of the cognitive tasks involved in public service translation and interpreting, there appears to be a growing consensus that training should take place at [a] higher education level because mediated professional settings require "smart" interpreters who can make informed judgments based on authentic practice as well as informed theoretical knowledge.

Another topic of debate, which affects both LIT and PSIT, relates to the nature of courses in terms of the languages of instruction. The greater part of these courses is "language neutral". In other words, they are imparted in a certain number of languages apart from the language of the country in question, with the most common languages being those of the European Union: English, French, German, Italian or Spanish. Regarding the USA, Mikkelson (2014: 12) significantly points out,

(...) that Spanish is the dominant foreign language in the U.S. and other languages, though spoken by large numbers of residents overall, do not account for many speakers in any given location. Therefore, the vast majority of the training programs that do exist offer courses in Spanish only, neglecting the other languages.

Finally, another point in the debate and one which is in line with those who defend PSIT in a legal context is one of those issues that Mikkelson refers to as "unresolved questions" (2014: 11). Here, I refer to the role of research in interpreter training, as I consider this to be fundamental to PSIT given some of its features. For example, in PSIT, languages and cultures which are practically unknown -also in training programs- come into contact and research is therefore necessary to make them known to one another and to develop proper initiatives. However, and in spite of the fact that it is generally acknowledged that instructors must be up to date on research and advances made in the field in order to include these in their teaching, it does not seem that this always applies to student curriculum. Among the arguments set forth are the lack of time, the lack of preparation by students, difficulties obtaining data, or instructors' background, as these have usually developed their competences working as freelance interpreters and have received scant academic preparation (Valero Garces, 2013; Valero Garces Vitalaru, 2014). In this vein, I am in full agreement with Hale (2007: 198) when stating: "If research in this field is to be promoted and its results used 
to inform both training and practice, training in research methods is crucial" (Hale, 2007: 198), as Napier and herself recently confirmed (Hale - Napier, 2013).

On the periphery of this latent controversy, my proposal focuses on formal training, research and practice in legal translation and interpreting (LIT) in a specific field: Public Service Interpreting and Translating (PSIT), also known as Community Interpreting (CI). Developing a specific training programme that covers all competencies and qualifications required for PSIT and LIT professionals has been the main objective of the programme since it was launched in 2001. At that time, ten language combinations were offered, in an attempt to meet the needs of the area. This particular feature was practically an exception in the European panorama. Other programs have followed lead over time, such as those offered at Heriot-Watt University, Edinburg, Scotland or in London Metropolitan University, UK. In the United States, the University of Maryland recently launched the Master of Professional Studies in Public Service Interpreting, offering regular instruction in high demand languages and a multilingual setting (Office of Extended Studies (University of Maryland) 2013, n.p.).

\section{Combining LIT and PSIT in postgraduate training. The MICIT as a case study}

The Master in Intercultural Communication, Public Service Interpreting and Translation (MICIT) (http://www3.uah.es/master-tisp.uah) is a postgraduate degree which has been operating as such since the academic year 2005-06. Being part of the EMT, the programme's instructional objectives are unified with those of other European universities, which enables cooperation on legal projects and initiatives funded by the EU Department of Justice (such as Grotius, Agis, Building Mutual Trust, SOS VICS or QUALETRA) and by the EU Life Long Learning programme (such as OPTIMALE and AGORA).

The MICIT is also integrated into a postgraduate programme and gives access to a $\mathrm{PhD}$ degree programme, two keys to added value that contribute to its recognition. The general objective is to provide students with the theoretical knowledge and the skills, abilities, and tools they need to act as linguistic and cultural liaisons between institutional, medical, judicial, and educational staff and the recipients of these public services who do not speak the contact language. The programme is based on a cross-fertilization between theory, practice and research.

\section{The MICIT syllabus}

The MICIT syllabus follows the EMT competences wheel for professional translators, adapted to the legal domain by the members of the QUALETRA project (EULITA n.d.) as seen below (Figure 1): 


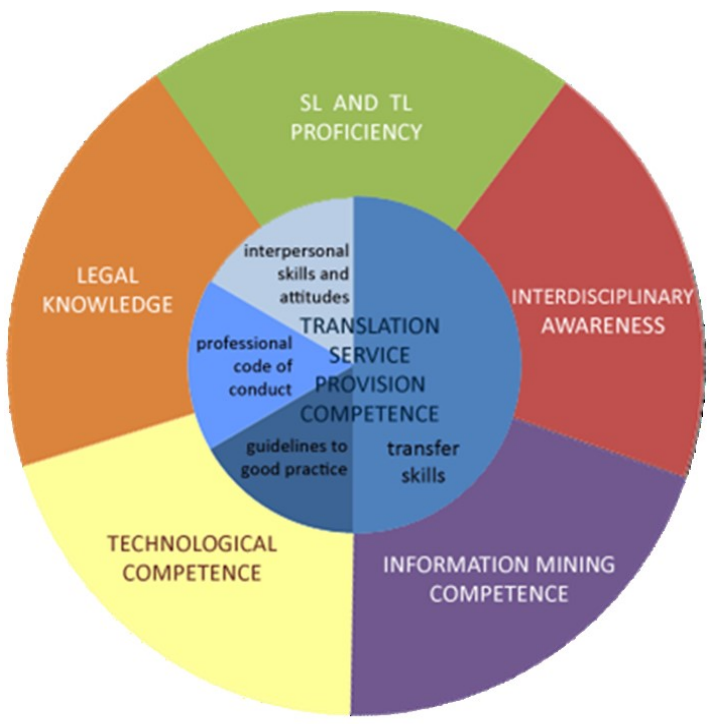

\section{QUALETRA}

\section{Figure 1 LIT competences (Scarpa \& Orlando 2014)}

The Master includes five different modules on different topics, adding up to

60 ECTS. These are offered in ten language combinations (with Spanish as source language) and distributed over one academic year. ${ }^{1}$ The modules and the corresponding subjects are shown in Table 1:

\section{Table 1 MICIT Syllabus}

\begin{tabular}{|c|c|}
\hline Modules & Subjects \\
\hline $\begin{array}{l}\text { I. Interlinguistic } \\
\text { communication } \\
\text { (online) }\end{array}$ & $\begin{array}{l}\text { Inter-linguistic Communication (5 ECTS) } \\
\text { Institutional Communication with Foreign-Origin } \\
\text { Communities ( } 7 \text { ECTS) } \\
\text { Techniques and Resources for PSIT (I) (6 ECTS) }\end{array}$ \\
\hline $\begin{array}{l}\text { II. Interpreting } \\
\text { and translating in } \\
\text { healthcare } \\
\text { settings (on site) }\end{array}$ & $\begin{array}{l}\text { Techniques and Resources for PSIT (II) } \\
\text { Interpretation in Healthcare Settings (language specific) (5 } \\
\text { ECTS) } \\
\text { Specialised Translation: Healthcare Settings (language } \\
\text { specific) (5 ECTS) }\end{array}$ \\
\hline $\begin{array}{l}\text { III. Interpreting } \\
\text { and translating in } \\
\text { legal, } \\
\text { administrative, } \\
\text { educational } \\
\text { settings (on site) }\end{array}$ & $\begin{array}{l}\text { Techniques and Resources for PSIT (III, } 2 \text { ECTS). } \\
\text { Interpretation in Legal-Administrative Settings (language } \\
\text { specific) (8 ECTS) } \\
\text { Specialised Translation: Legal Settings (language specific) } \\
\text { (5 ECTS) } \\
\text { Specialised Translation: Administrative Settings (language } \\
\text { specific) (5 ECTS). }\end{array}$ \\
\hline $\begin{array}{l}\text { IV. Internship or } \\
\text { Practicum }\end{array}$ & Internship in public/private institutions (5 ECTS) \\
\hline $\begin{array}{ll}\text { V. Master's } \\
\text { Thesis }\end{array}$ & Research project (9 ECTS) \\
\hline
\end{tabular}

Slavonic Pedagogical Studies Journal, ISSN 1339-866o, Volume 5 Issue 2, September 2016 
The programme has a fundamentally practical focus based on the following aspects:

- Specialized training in different specialties using authentic material;

- Practical knowledge of the theory acquired in the initial training sessions;

- Continuous assessment applied to both training methodology and evaluation criteria;

- Traditional classroom teaching and e-learning methodology;

- Trainers' profiles include both academics and practitioners (translators and/or interpreters).

- Students' active participation by sharing their experiences related to translation and interpreting in different fields;

- Students' internships providing practice in real working conditions;

- Development of links with different national and international leading academic and research institutions in PSIT.

- Application of acquired competencies during the completion of the Master's Thesis on a topic related to PSIT.

Blending online and on-site classes seems necessary in order to facilitate students' attendance, given that around $35 \%$ have work or family responsibilities, and around $60 \%$ of students come from different cities or even different countries, as can be seen in the section on students' and teachers' profile. A maximum of twenty students per class and a minimum of eight students per language pair are the minimum requirements for a course to be implemented each year.

The MICIT also combines training in translation and interpreting. This remains an unexplored but controversial issue among both the programme followers and detractors, with little research about the benefits or disadvantages of such an approach. At least in the case of Spain, this approach has proven to be very successful, as it seems to reflect actual practice in the PSIT and LIT area, where most practitioners are forced to perform both tasks for different reasons.

The annual European Master's in Translation (EMT) event held in Brussels in March 2014 (22-23) was part of a joint conference organized for the first time by both the European Commission Directorate-Generals for Interpretation and Translation. The focus of the two-day conference was on institutional and public service translation and interpreting, with examples of best practices in training courses. Members of the programme were invited by the EU DGT to present the MICIT to the audience. This, without a doubt, shows further recognition of the programme's quality.

\section{Rationale behind the syllabus}

The significance of this degree and its continuing growing success is mainly rooted in the fact that society continues moving towards a multicultural reality, one which has given way to new needs and challenges to be addressed. Thus, as society progresses towards a multicultural model and new and/or complementary legal regulations come into effect (e.g. European Parliament and Council of the European Union, 2010), the need for legal 
translators and interpreters (T\&I) and their professionalization becomes more urgent.

The MICIT fills a training gap at higher education levels and thus it contributes to the creation of competent and efficient liaisons as opposed to bilingual volunteers or untrained T\&I, still common in the legal context when it comes to less spoken languages (Ortega Herraez, 2011). That is the reason why the MICIT degree is aimed at university graduates fluent in Spanish and the traditional English, French or German, but also in Arabic, Bulgarian, Polish, Portuguese, Romanian, Russian, or Chinese, the languages of migrant communities that are generally in need of translation and interpreting services.

\section{Students' and teachers' profile in the MICIT}

Before moving on, and in order to understand the specific nature of this training and the interest in the practices and research presented in the following pages, it seems necessary to discuss two fundamental components: students' and teachers' profile.

The number of students has been increasing each year growing from 40 students in the first edition (2005-2006) to more than 300 hundred applications, and 105 registered in the 2012-13 edition. Their country of origin is also changing, having increased to over 15 nationalities. This multicultural profile has enriched the training of our students by providing them with a fascinating multicultural perspective.

The teaching staff for the training programme has also been growing and changing throughout the years. Our unique and interdisciplinary educational philosophy is grounded on university lecturers and experienced practitioners and stakeholders, which undoubtedly is one of the programme's most visible strengths. It ensures sound theoretical training and high-quality practical training. It also allows for the exchange of views among in-house staff and external trainers. The multicultural and multidisciplinary origin of trainers contributes to the fulfilment of our objectives. The teaching staff is selected according to two major categories (with some of the trainers belonging to more than one category):

1. Academics: professors, senior lecturers, lecturers and part-time lecturers, both full-time employees at the UAH and also visiting lecturers from other highly reputed Spanish and international universities and international higher-education translator and interpreter training centres.

2. Professional translators-interpreters or field experts, that in the case of the LIT are: professional translators-interpreters on a full-time basis with Spanish top-institutions (such as the Ministry of the Interior, the Ministry of Foreign Affairs, Refugee and Asylum Seekers Office, Ministry of Justice, etc.) and freelance translators-interpreters with extensive professional experience in a wide variety of settings related to Public Services, as well as professionals with expertise in other fields (legal, administrative, healthcare professionals on a full-time basis with Spanish institutions and with extensive professional experience in a wide variety of settings related to Public Services). More than $30 \%$ are translation and interpreting practitioners and approx. $30 \%$ of the 
visiting academic staff are also sworn translators or have experience as translators/interpreters.

This marriage of highly qualified academic staff, on the one hand, and practitioners, on the other hand, both national and international, provides students with the perfect connection between the theoretical and practical lessons taught in the classroom and the workplace. Together with the applied active methodology, this contributes to the success of the high rates of enrolment and external recognition. According the survey in El Mundo June 15 2013, MICIT is one of the top twenty MA in Spain- this being the fifth year that the MICIT has been awarded this distinction.

\section{Training in PSIT in the legal context}

As we have commented previously, special emphasis is placed on the legal field within the Master's syllabus. There is a specific module devoted to T\&I in the legal field (Module III) and two more (Module IV (Internships) and V (Master's Thesis)) are also focused on the legal field depending on the student's individual interests.

Module III offers training in Legal and Administrative Translation and Interpreting (total 20 ECTS out of 60) and consists of 4 subjects:

1. Techniques and Resources for PSIT (2 ECTS)

2. Interpretation in Legal-Administrative Settings (language specific) (8 ECTS)

3. Specialized Translation: Legal Settings (language specific) (5 ECTS)

4. Specialized Translation: Administrative Settings (language specific) (5 ECTS).

Since the Master is focused on professional preparation and, as such, is fundamentally practical in nature, the classes, as has been indicated, are devoted to honing the skills which must be acquired (consecutive and simultaneous interpretation, bilateral and whispering interpretation, sight translation, translation of texts and glossary development). Classes are intensive, 4 hours a day during 10 weeks and are compulsory, on-site and given to small groups separated according to their language combination. In class, students practice using authentic texts provided by the institutions or associations or using role plays in which professionals from other fields also participate (attorneys, judges, social service officials, non-profit staff, etc.). Thus, the master's multi-faceted methodology is experienced in conjunction with exposure to real documents, sent by the institutions and enterprises which collaborate with the MA programme. The practice acquired becomes even more intensive during the internships which must be completed at these institutions, as we explain in the following module. Students are continually evaluated throughout the programme.

\section{Internships}

Since the final goal of the MA is to provide a well-rounded education for future T\&I professionals by exposing them to real-world situations, the instrument that best contributes to preparation for the profession is, without 
any doubt, our internships programme. In order to achieve this, more than 90 agreements with public and private institutions have been signed. The list includes conventions and agreements with state and local administration agencies (Home Office, Foreign Office, Ministry of Justice, NGOs, international organizations) which allow students to complete the compulsory period of internships in courts, town halls, schools, police stations, charity associations, hospitals and so on. ${ }^{2}$

Each student is granted a post at any of these institutions according to a set of preferences the students manifest through the completion of a form and the writing of a cover letter, as well as their transcript. The institutions must provide a mentor for each student, who will guide them through the particulars of the institution. The University also provides another mentor in charge of the supervision of the translations and correct compliance with the internship. The student, apart from completing the internship, must write a report about the tasks performed and complete a questionnaire on satisfaction. The students are graded using the feedback provided by both mentors and the coordinator of the internships programme, who is in charge of overseeing the correct compliance of the internship and of grading the report written by the student. The coordinators of the internship programme also attend the meetings organized by the institutions which have an internship agreement with our university. These meetings bring training bodies together in order to exchange information about experiences and practices. (For more information about methodology, agreements, etc. see Valero Garces, 2010: 16-24; Valero Garces, 2011: 121-51).

As for the legal domain, approximately $30 \%-40 \%$ of the students complete their internships in state institutions and /or tasks related to the legal setting. This is the field which is of most interest to students. It is also the field in which there are more signed agreements with internship sites, where tasks are performed which are either directly or indirectly related to the legal setting. The rest of the student internships are distributed in the following way: between $20 \%$ - $25 \%$ of the students complete their internship in the healthcare sector; about $30 \%$ of the students complete their internship in the business sector and around $10 \%$ in education settings.

As for the value of this practicum, most students agree that internships have helped them to see up close what the work environment with foreign population in the public service setting is like. They specifically call the attention to the fact that they are able to experience what an interpreting job is like in a real situation because, even though they did role-plays in class, interpreting with their classmates in class is not the same as with a person that really needs someone to communicate with as much precision as possible, and must make decisions quickly. As for translation, students see translation assignments given by the institutions as a perfect way to put the legal translation class into practice as the need to develop their organizational ability when faced with a longer translation than the ones they had done in class as preparation for a possible assignment.

An example taken from a student's report illustrates these words: 
Qatar Embassy, Madrid. Spring 2013. Spanish - Arabic.

In general, all of the translation classes have helped me to have greater skill when translating to Arabic and of course, the legal-administrative module is the one that comes closest to the kind of translations that are done at the embassy. I am very happy with the month I have had of the internship, I don't think I could have had a more rewarding internship. I have managed to acquire skills and confidence when translating to Arabic, to be faster and more efficient and get an introduction to the field of translation in institutions. It has been a really enriching experience in all areas in which I have learned a lot.

\section{Research in LIT}

The training programme includes a significant research portion through the MA Thesis. As already stated, the main objective of this research is to initiate students into the scientific analysis of the socio-cultural reality that surrounds them and to add knowledge to what they have learned in the classroom and/or institutions during their internships. The underlying assumption is that the information obtained could lead them (and the experts, institution representatives, or the public in general) to envision solutions to problems or to ask questions unknown to the dominant majority. In fact, some of the actions that are already underway or are about to start in PSIT have been highly influenced in both their design and implementation by research initiated by graduate students. Students receive clear and accurate information early in the course about what, how and when they must submit a final paper between 40,000-50,000 words on a topic related to PSIT or LIT. Assessment includes both evaluation of the written examination and oral presentation.

Another important reason to recognize the value and the need for research in PSIT is the fact that sometimes this is the only direct, effective way to obtain deeper knowledge of ethnic minorities and their culture and to gain a firsthand understanding of their specific problems or degree of adaptation. This knowledge is an important component if a multicultural society is to be attained. Additionally, the students are often members of these specific communities and it is therefore easier for them to gain access to the minority group.

As project advisers and in line with other researchers and trainers (Hale Napier, 2013; Swabey - Nicodemus, 2011; Shlesinger, 2009), our experience shows that the research results contribute, firstly, to improving teaching quality and, secondly, to establishing partnerships with institutions.

According to data from the catalogue/data base of MA thesis titles created in 2010 for internal use we had 438 MA thesis catalogued as of December 2013. This catalogue/database consists of a series of files or compartments which include groups of file cards organized according to topic and which are identified by the title, author's name, year MA thesis was defended, language combination, key words, and a summary in English, Spanish and the other working language if there is one.

Taking into account the main fields of study within the training programme, we can define five categories with the inevitable overlaps: healthcare; 
education; legal, terminology and resources and culture and mediation. If we focus on the specific fields, the total distribution of the MA thesis between these three categories reveals that the greatest percentage is in the legal setting $(8.44 \%)$ followed by the healthcare setting $(4.56 \%)$ and lastly the educational setting (3.65\%). However, if we consider the distribution according to linguistic specialties (Figure 2) we can see variations. For example, while in the Chinese, Polish, Romanian and Russian-Spanish specialties, the highest percentage is in the legal field, in English-Spanish the percentage is the same for both the legal and healthcare fields and greater than the educational field. In the Arabic-Spanish concentration the percentage is the same across the three fields. On the other hand, in the Chinese-Spanish and French-Spanish concentrations the highest percentage of the MA thesis is in healthcare, followed by legal and lastly, the educational sector. We can also see that the lowest percentage of MA thesis centred on the healthcare sector occurs in the Polish and Russian-Spanish concentrations, while in the Romanian-Spanish concentration, the lowest percentage is in the educational sector (Valero Garces - Vitalaru, 2014: 85).

\section{Percentage MT Fields \& Languages}
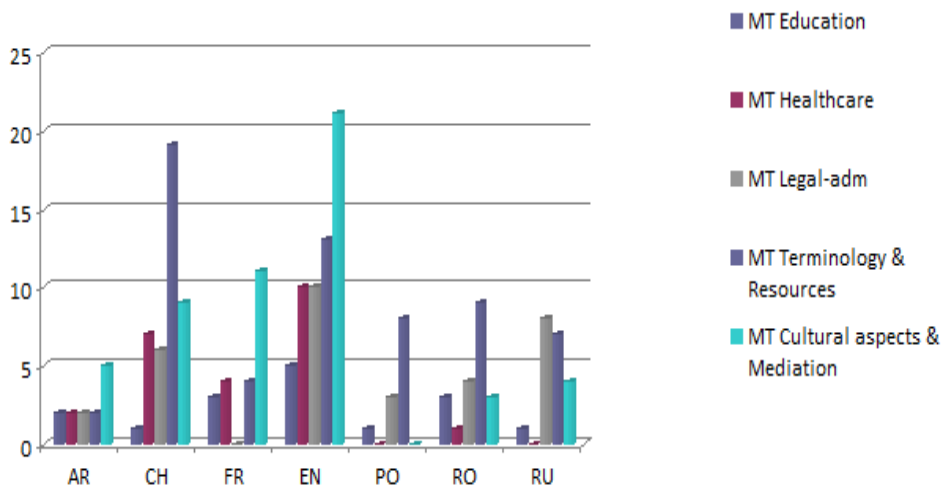

Figure 2 MA Thesis: Educational, healthcare, and legal sectors by concentration

Focusing our attention on legal aspects and on the content of the MA thesis, we can establish four general groups or categories according to topic, though keeping in mind the lack of clear limits between these categories. They are: a) descriptive analysis or comparison of the legal / judicial systems or specific legal aspects in different countries; b) issues related to legal translation; c) issues related to legal interpreting, d) issues related to training; e) terminology and resources. Some titles in English follow to illustrate the different categories. It is a literal translation from Spanish, the original language of the MA thesis. 
- Study of the legislation on the right to interpretation and translation in criminal proceedings in the EU-27 and the adoption of the new European directive by Livadaru, A. (2010-11).

- Comparison of Spanish and Chinese legal language. Discussion of translation difficulties by Tan Yanping (2011-12).

- Errors in the translation and legal interpretation by Torres, M. (2009-10).

- Terminology and legal translation. Spanish police system vs. Romanian police system by Micu, A. (2011-12).

A series of initiatives either already in motion or about to be initiated stem from these research studies. The main goal is to circulate the information from this research and build interest in the scientific community and among the students themselves. This often leads students to give form to their efforts through a doctoral thesis or more detailed studies on issues yet to be explored. Some of these initiatives are:

- The already mentioned on-line database or catalogue of MA thesis which soon could be consulted by the students at the university library (http://www.uah.es/biblioteca/e_buah/ebuah.html).

- The publication of an on-line multilingual scientific journal, FITISPos-IJ, an annual publication launched in April 2014 which includes a selection of Master Thesis as working papers and which will hopefully be a forum of discussion for MA students, scholars and trainers interested in PSIT.

- The development of doctoral theses delving more deeply into legal issues. Some of these have already been completed, while others are in their final stages. Sample titles include: "Legal and Administrative Terminology: design and development of a trilingual glossary (Spanish-Romanian-English)" by Bianca Vitalaru (2012); or "Translation and Interpreting in Spain in the case of gender violence" by Anca Bozer (2014).

\section{Conclusions}

This article focuses on formal training, research and practice in legal translation and interpreting (LIT) in a specific field: Public Service Interpreting and Translating (PSIT). Assuming that PSIT originates within and for the institutions and the public services, links between PSIT and LIT were discussed and a training initiative was presented as a case study: The European Master's in Intercultural Communication, Public Service Interpreting and Translation (MICIT). Its programme combines postgraduate training, research and practice in the PSIT area. This paper has concentrated specifically on the legal domain, focusing our attention on two specific modules (internships and research).

The study shows that PSIT and LIT are linked areas with no clear borderlines, and that translators and interpreters, irrespective of the setting, share similar challenges and need similar training adapted to the specific situation. The MICIT syllabus combining on-site training, internships and research has proved to be relevant as being the primary element connecting in-class training with practice in real settings, but also because it is a route to connect institutions to the academia and the students. 
Generally speaking, the design of the curriculum of the MICIT has been highly influenced, on the one hand, by the continuous debate on the lack of connection between academic training and the labour market and, on the other hand, by the fact that the transfer of knowledge requires research. Alliances and cooperation are needed with all the agents that somehow (might) intervene in the T\&I working environment, but it also requires students to be trained in I\&T skills. As a case study the MICIT combines all these elements and it is intended to serve as a further step towards the professionalization of PSIT and LIT. Internships have been demonstrated to be useful tools to integrate class instruction in the working place; and research has also contributed to add information and knowledge or ask questions about specific topics underdeveloped or unknown to the dominant majority (differences between the Chinese and Spanish legal system) or to envision some solutions (checking common errors in translated texts, analyse the interpreter's roles) as well as to help improving the MA itself (providing authentic materials to be used in class).

\section{Bibliographic references}

AGORA. 2013. Agora - Transnational Placement Scheme For Translation Students. Accessed 12 December 2014. Available online: https://http://www.academic-projects.eu/agora/default.aspx

AUTOR 2008. Investigacion y Practica en Traduccion e Interpretacion en los Servicios Publicos. Desafios y Alianzas. Alcala: Universidad de Alcala. 334 ISBN: 978-84-8138-773-5.

AUTOR 2010. The Value of Internships in PSIT. Looking out of an open window. FORUM: Revue internationale d'interprétation et de traduction / International Journal of Interpretation and Translation, vol. 8, n. 2, pp. 221240.

AUTOR 2011. Design, Implementation and Evaluation of a Programme on Intercultural Communication and Public Service Interpreting and Translation. In KAINZ, C. - PRUNC, E. - SCHOGLER, R. 2011. Modelling the Field of Community Interpreting: Questions of Methodology in Research and Training. Berlin, Munster, Vienna, Zurich, London: LIT, pp. 121-51. ISBN 978-3-643-50177-6.

AUTOR 2013. Formación de traductores e intérpretes en una sociedad multicultural. El programa de la Universidad de Alcalá, Madrid. In Cuadernos de ALDEEU, vol. 25, pp. 215-238, ISSN 0740-0632.

AUTOR - VITALARU, B. 2014. La importancia de la investigacion basica en TISP. Una puerta entreabierta para el avance del conocimiento. In FITISPos International Journal, vol. 1, n. 1, pp. 76-91. ISSN 2341-3778.

BANCROFT, M. - RUBIO-FITZPATRICK, L. 2009. The Community Interpreter: Professional Interpreter Training for Bilingual Staff and Community Interpreters. Ellicott City, MD: Culture and Language Press. ISBN 9780982316672.

BENMAMAN, V. 1997. Legal interpreting by any other name is still legal interpreting. In CARR, S. - ROBERTS, R. P. - DUFOUR, A. - STEYN, D. 
1997. The Critical Link: Interpreters in the community. Amsterdam: John Benjamins, pp. 179-190. ISBN 9789027216205

BMT (Building Mutual Trust). 2014. Building Mutual Trust. A Framework Project for Implementing EU Common Standards in Legal Interpreting and Translation. Criminal Justice Programme of the European Union. Available online: http://www.buildingmutualtrust.eu/

CORSELLIS, A. 2008. Public Service Interpreting. The First Steps. London:

Palgrave Macmillan. ISBN 978-0-230-58195-1.

EMT (EMT Expert Group). 2014. European Master's in Translation (EMT).

European Commission. Available online:

http://ec.europa.eu/dgs/translation/programmes/emt/index_en.htm

EULITA (European Legal Interpreters and Translators Association). QUALETRA. EULITA. Available online: http://www.eulita.eu/qualetra

European Parliament, and Council of the European Union. 2010. Directive 2010/64/UE on the right to interpretation and translation in criminal proceedings [Translated Directive 2010/64/UE of the European Parliament and of the Council of 20 October 2010 on the right to interpretation and translation in criminal proceedings], Official Journal of the European Union OJ 2010280.2 L 28 online: http://eurlex.europa.eu/LexUriServ/LexUriServ.do?uri=OJ:L:2010:280:0001: 0007:en:PDF

HALE, S. B. 2007. Community Interpreting. Hampshire: Palgrave MacMillan. ISBN 978-0-230-59344-2.

HALE, S. B. - NAPIER, J. 2013. Research Methods in Interpreting. London: Bloomsbury. ISBN 9781441168511.

KAINZ, C. - PRUNC, E. - SCHÖGLER, R. 2011. Modelling the Field of Community Interpreting: Questions of Methodology in Research and Training, Repräsentation - Transformation. representation - transformation. représentation - transformation. Translating across Cultures and Societies. Vienna: LIT. ISBN 978-3-643-50177-6.

MIKKELSON, H. 1996. Community Interpreting: An emerging profession. In Interpreting vol. 1, n. 1, pp. 125-129. ISSN: 1384-6647.

MIKKELSON, H. 2014. Evolution of Public Service Interpreter Training in US. In FITISPos International Journal, vol. 1, n. 1, pp. 9-22. ISSN 23413778.

MILlAN, C. - BARTRINA, F. 2013. The Routledge Handbook of Translation Studies. London, New York: Routledge. ISBN 9780415559676.

Office of Extended Studies (University of Maryland). MPS in Interpreting. University of Maryland, Available online: http://www.oes.umd.edu/index.php?slab=interpreting

OPTIMALE. 2013. Optimising translator training in Europe 2014-2020: Optimale Declaration. Paper presented at the Optimale Final Conference, Rennes, 7th June 2013. Available online: http://www.translator-training.eu ORTEGA HERRÁEZ, J. M. 2011. Interpretar para la Justicia. Granada: Comares. ISBN 9788498367010.

PEREZ, I. - WILSON, C. 2011. The interlinked approach to training for interpreter mediated police settings. In KAINZ, C. - PRUNC, E. SCHOGLER, R. 2011. Modelling the Field of Community Interpreting: 
Questions of Methodology in Research and Training. Berlin, Münster, Vienna, Zurich, London: LIT, pp. 242-262. ISBN 978-3-643-50177-6.

PÖCHHACKER, F. 2004. Introducing Interpreting Studies. London New

York: Routledge. ISBN 9780415268875.

RUDVIN, M. - TOMASSINI, E. 2011. Interpreting in the Community and Workplace: a practical teaching guide. Basingstoke: Palgrave Macmillan. ISBN 978-0-230-30746-9.

SASSO, A. - MALLI, K. 2014. Trying to fit a square peg in a round hole. In FITISPos International Journal, vol. 1, n. 1, pp. 42-50, ISSN 2341-3778.

SCARPA, F. - ORLANDO, D. 2014. What it takes to do it right. An integrative EMT-based model for legal translation competence. Presentation for the Final QUALETRA Conference. Available online: http://www.eulita.eu/qualetra-final-conference-presentations.

SHLESINGER, M. 2009. Crossing the divide: What researchers and practitioners can learn from one another. Translation \& Interpreting, vol. 1, n. 1, pp. 1-14.

Sos-Vics (Speak Out for Support). 2014. Speak Out for Support. Universidade de Vigo. Available online: http://cuautla.uvigo.es/sos-vics/

SWABEY, L. - NICODEMUS, B. 2011. Bimodal Bilingual Interpreting in the US healthcare systema. In Advances in Interpreting Research. Inquiry in action. Amsterdam, Philadelphia : J. Benjamins. Vol. 99, pp. 1-4, ISBN 9789027224477.

WADENSJÖ, C. 1998. Interpreting as Interaction. Londres, Nueva York: 336 Longman. ISBN 0582289114

\author{
Carmen Valero Garcés \\ University of Alcalá \\ Dept of Modern Philology \\ C/ Trinidad, 3 \\ 28801- Alacla de Henares, Madrid \\ Spain \\ carmen.valero@uah.es
}

